\title{
The Discussion about the Maintenance of Authenticity of the Culture and the Relationship between Hosts and Guests of Debugging in the Development of Ancient Town Tourism --Take Lijiang Ancient City as An Example
}

\author{
Xianzhai Fang \\ Xinyang University, 467400
}

\begin{abstract}
In recent years,Heritage tourism has become the popular tourism products widely.But there are some behavior of blind developments that destroy the aboriginality of the world cultural heritage.The aboriginality of the culture is the important standard of the world cultural heritage. The stage authenticity of tourism comes from the local reality in real life instead of the reality of native culture.It makes the native culture more ornamental through refining and processing of the art.Lijiang ancient city,one of the world heritage, must respect and maintain the native culture.Morever,Lijiang should adapt to the culture instead of destroy. The development of the heritage site tourism should deal with the relationship of the original residents and tourists suitably to make it develop harmoniously.

Key words: cultural heritage; stage authenticity; relationship between the host and the guest; Lijiang ancient city
\end{abstract}

\section{Introduction}

In recent years, China's tourism industry is developing from the new growth point of economic to the pillar industry of national economy and is spaning from the tourism country to the the world tourism power.The world heritage tourism is increasing fast and has become the mainly production of many tourist destinations.China' $\mathrm{s}$ national tourism administration made "China' s century tourism" as the slogan in 2000 and made the twenty-seven items of the world heritages as the important tourism productions to promote for guests. Then, these world heritages turned into the 
tourist destinations that tourists at home and abroad looking forward to.Heritage tourism has become a widely popular tourist products.However,there exists phenomenons including overdevelopment of tourism resource; overconstructions of tourist facilities too much tourists and the tendency of artificialization; urbanization and commercialization.Therefore, the authenticity and the integrity of natural and cultural heritage in a lot of scenic spot has been ruined and even lost their prototype forever.These blind development activities made the heritage become a pity or made the heritage become a relic.Both of the two behaviors should be avoided as far as possible in the heritage tourism development.

\section{Research overview}

China joined the world heritage organization in 1985.Our country started to expand the study of the heritage tourism after the first world heritage' s appearance since 1987. The development and utilization of world heritage related with the tourism first.But there wasn' t the concept of the heritage tourism.It was not until 1999 that Wangdawu apply the concept of the heritage tourism.In recent years,scholars research the world heritage tourism the following aspects:the research about the value、 the impact the function and the characteristic;Wangxin(1995)think that the world heritage sites possess the attribution including the tourist attractions 、 education bases and the community identification marks. Taowei(2002)summarized the general characteristics of world heritage in our country, which contained the category of the world heritage,the spatial distribution become more sparse varying from the east to the west,the natural and humanistic integrated.He also did the scientific classification of world heritage of our country and analyzed the history, art, landscape, ecology, philosophy and other aspects of value of heritage systematically[1].When it comes to the function of the heritage,Xieninggao(2000), one of the world heritage experts, think that the heritage have the function of sightseeing, scientific research, the spirit of patriotism education, inspired wisdom and etc,which are the function of various culture and science and education activities with particular emphasis that its function is not only tourism[2].For the research of the sustainable development of the world heritage tourism destination, Weixiaoan considered that the marketization of heritage 
resources of development was a realistic choice of tourism economic development with least environmental costs[3]. On the one hand,tourism development provided capital for heritage conservations, on the other hand,the damage was caused by improper development of heritage because of too much tourists (Fanlingyun and etc.2003 ) [4].Yanmei(2003) built the culture construction system of the sustainable development of the tourism of the world cultural heritage[5].There is very few researches about heritage tourism market.Liuchangxue(2005)analysed potential characteristics of the ancient village tourist behavior from two areas of gravitational pull and push factors with the examples of XiDi and Hong Cun,which are world heritage by factor analysis.It has a certain reference value for the world cultural heritage of marketization development.The article bases on the world heritage,the ancient city of lijiang as an example,attempt to discuss from the stage authenticity of heritage tourism and the relationship between hosts and guests.

\section{The analysis of the cultural authenticity and the stage authenticity of the heritage tourism}

\subsection{The cultural authenticity of the heritage tourism}

Cultural authenticity is an important criterion to evaluate the World Cultural Heritage and it is one of the most important criterion of the tourism value.The cultural authenticity of the heritage tourism is the reality of tourism objects,including objective criteria of experts and the reality of object in tourist perception. "the buildings and blocks which have historic value shall be properly kept instead of being destroyed" (Athens charter,1933). "Regardless of size, including cities, towns and historical central areas and residential areas, including its natural and artificial environment... They can be used not only as the historical witness and reflect the value of the town of traditional culture(Washington charter,1987)The above two declaration emphasize the reality of tourism objects, in tourism practice,the authenticity of tourism objects directly determines the authenticity of tourism experience.In Mac Cannel' $\mathrm{s}$ “ theatrical reality" theory,the "background" of tourism environment is real and the "proscenium" is not real from the view of the experts.In the tourism industry, however,the object 
reality in an absolute sense is often hard to do.In developed countries, in fact, the object reality of expert standards are still widely used in the development of tourism destination.After years of rapid development, the tourists of lijiang, a total of 5.3093 million people, including 400700 overseas tourists and domestic tourists 4.9086 million person-time by 2007.But there existed convergence and singleness in process. The development was simply interpreted as commercial reconstruction of traditional street or leisure industry;a large number of people moved out of the original residences and the cultural authenticity of the $\mathrm{NaXi}$ was nearly ruined.It laid emphasis on the recovery and construction of residential buildings merely and neglected the function of discovery.In the tourism development, Most exploitations located in the development of the comprehensive function.But they were actually a kind of fuzzy function orientations.However, business opportunities appeared with millions of tourists visiting the ancient city.It attracted a large number of outsiders. They rent houses to open the inn and the bar into the old town,thus changing the original blocks into tourism area of business.As is shown in the data of heritage administration in the old city,there were more than 30000 people before 1996. However,there were only 6000 people in 2011.A large number of indigenous people moved out of the ancient city and buy a house in the new town. Their original house was rent for those foreign merchants. "The replacement will inevitably lead to cultural change. The very important reason that Lijiang old city is on the list of UNESCO world cultural heritage protection is that the ancient city of reserved

'living culture'--the living state of NaXi." Yet "living culture" is the soul of Lijiang old city. The soul of the ancient city of and the travel value, is not in the bridge or in the water.It is in the original inhabitants of the ancient city, and exists in the culture of $\mathrm{NaXi}$ nationality.Lijiang ancient city, as the world cultural heritage,has its intrinsic value, including the value of historical、cultural aesthetic 、artistic and scientific, is the foundation of the system of the world cultural heritage value;Lijiang old city provides the real life that is common wealth of human society with a strong social public at the same time.People can get a sense of belonging and identity from it.Therefore, this kind of social value is the core content of value system and it is the root cause of protecting and using. We must see that tourists are attracted because of this resource and value.Once the city loses "the characteristics of desirable" as a world heritage site, visitors will not tour the 
ancient city.Since the 1990s, the authenticity of tourism objects gradually has been taken seriously.We have to respect and maintain the local culture, to adapt to the local culture rather than to destruct of the local culture.Since we earn the money and get the pleasure from the city,we have to take the responsibility to protect the ancient city and the culture of ancient city with the locals.Local residents should even more take the responsibility to inherit $\mathrm{NaXi}$ and DongBa culture in the production and living because that the world cultural heritage is not only belongs to lijiang but also belongs to the mankind of all.

\subsection{The stage authenticity of the heritage tourism}

"Stage authenticity" was originated in the theory of Erving Goffman first.He compared the life to a stage and put forward the point of view of "the front stage" and "the back stage" . "the front" refers to the open space where guest or customer contacted with service staff.Yet "the back" refers to the closed space where is preparing for the performance of the front.MacCannel,one of the American sociologist,developed and extented Goffman's theory.He thought that most of modern tourism belonged to the experience of "stage authenticity in tourism" .In tourism experience, although tourists "entered into the back in real life" ,visitors saw "the decorated back" in fact as a result of the tourism behavior of organization, socialization and institutions . There were only a handful of the tourists who "run away from the hotline,avoided hot spots" could get the real experience of "tourist places" .[8]The "Stage authenticity" and "Pseudo folk" couldn' t be compared.Some scholars pointed out that "the so-called 'pseudo folk' refered to the folk custom items that was patchworked 、 random packing or fantasy and the all kinds of explanation, folk legends, stories that was hard sticked up without any local cultural ecology exsiting in the man-made attractions".[9]As you all know, any destination is likely to leave their native culture "come clean" [10].In one sense, the folk culture tourism development pattern of original natural style is a way of suicide[11].Tourism development destinations showed theatrical folk with symbolic meaning to visitors, thus making promotes for protecting the native folk culture with no doubt.Stage authenticity was derived from the reality in real life,but it was distincted with the real of the native culture itself.It made the native culture appear more real through processing and 
refining of art.Therefore, the "Stage authenticity" is not equal with "Pseudo folk".

Essentially, tourism is " a civilized way of life" , " a kind of cultural phenomenon".Lijiang as a world cultural heritage,it appeals to the tourists by material culture and non-material culture.Its composition included the streets and historical buildings. Among them,the street is the core part of the formation of historical blocks which kept its original form;historic buildings included frontage, residential buildings and cultural relics and so on.In this respect,the lijiang ancient city was preserved well, but there are too many problems including too much street business store,the overthick commercial atmosphere and the noisy environment atmosphere.As the non-material in the ancient city, it should cover the pattern of streets and the location as well as the formation of space; the relationship of space among the building,greening and opening; the internal and external appearance of historic buildings, such as the relationship between the surrounding environment and the location,including size, form, style, material, construction decoration; the relationship between the natural and artificial environment;history function and the role it played;the residents living culture and the way of life.As so many indigenous moved out,foreign businessmen lived in with a large number of rental shops,thus making lijiang old city as ancient relics.It lacked the original residents way of life and became a stage of boisterous tourism business. The old city should provide tourists with real life place and the original residents could get a sense of belonging and identity at the same time because of a strong social public of the ancient city.

There are four forms of the stage authenticity that lijiang old city provide for the tourists as the world cultural heritages, including the true culture provided by the local people;modified culture provided by the local culture; the true culture provided by outsiders; modified culture provided by outsiders. When the tourists are increasing in the old city, there exists dangerous. The tourism city provides the tourists with more and better cultural experience in the fierce competition ,neglecting the protection of the local culture,making the local culture ruined.Or when cultural performance is particularly true, it obscures the boundaries of the local cultural heritage and performance, which can distort the local cultural heritage that was remained behind the "firewall" .The tourists pursuit "authenticity" of traditional culture in the tourism, but people who pay for leisure 
and people who "culture performance" to make a living are difficult to achieve the real cultural communication. When "culture performance" become the norm, the local residents may have changed way of life and has become a prop for stage.

\section{Residents and tourists--adjustment between "hosts" and "guests"}

Compared to other domestic historic city, lijiang old city is the model of the ancient city that is well preserved overall.It was built up relying on three mountains,organically and completely united with the nature.Tile-roofed house arranged in close order surrounding by green mountains. The scenery is beautiful.The vivid model of residential buildings in the city and the exquisite decoration is the crystallization of the technology and culture in NaXi.At the same time, Lijiang old city contains rich traditional culture of $\mathrm{NaXi}$, centrally embodying the prosperity and development of the national minority. That the street of the city, architecture and the courtyard people lived in show the profound and rich historical culture.DongBa culture which has the rich connotations or BaiSha murals and the other traditional art also left a precious property of human civilization particularly.Cultural tourism is widely regarded as the best way to recover the economy of the cities by using world cultural heritage resources,lijiang old city also used the shortcut.But we should face up that the tourism development of ancient towns, ancient villages and historical block directly led to the change of social structure in the local.As Longyingtai,one of the scholars in Taiwan,critically pointed out that the original indigenous culture what we cherish was removed and emptied after the original residents moved out.It was then made very beautiful and it was then put in a kind of new form of the capital culture as the entering of a certain class of people who are rich in consumption. There were immediately increasing dealers and floating population where there was once an original single local community.The relationship between the hosts and tourists became prominent and sensitive than before as they contacted directly.This is a problem in the process of tourism development that every world heritage site must face.Since the development processes of tourism are different and the social and economic conditions differ in heritage sites. Therefore,the way of solving the relationship between the host and the 
guest that can be applied to one place could not be applied to another place.The mode that Lijiang adopt to develop tourism to make the foreign tourists and the indigenous inhabitants of peaceful coexistence or the foreign culture and the $\mathrm{NaXi}$ culture of harmonious coexistence is the problem that the lijiang old city must face in the tourism development. There were three types of the indigenous in the old city by the way that the original residents and tourists contacted.The first type were the local people who were involved in tourism industry on the first line,such as traveling guides, food service, receptions of the scenic spot.The next type were the local residents who were affected by tourism practitioners in the family. The last type were other residents of the community. The way of contactions that the residents and tourists differs led to different response for the tourism. The different reactions would affect the relationship between the hosts and the guests as well as involving the image of the local tourism. To pay special attention to the education work of tourism community and gave the local residents the travel consciousness systematically. There was also necessity to make the local residents fully understand the tourism influence on local society,economy and culture.in the meantime,educating people to correctly understand and conscientiously to protect their own culture (such as recognition of $\mathrm{NaXi}$ in lijiang and other ethnic people's social life, customs and life interest, culture, arts and crafts, ethnic and religious belief and other distinctive and artistic value, thus drawing the old city residents to pay more attention to protect the historic building and have a sense of pride on its life forms), to known the importance to protect the natural、 ecological and cultural environment,to train people how to get along with tourists friendly.For some parts with positive development of tourism in our country,especially the regions where the economics were underdevelope, There were necessities to carefully study and treat about how to let local residents and tourists in harmony through all kinds of education,how to raise awareness of the cultural preservation and the ecological environmental protection consciousness of local residents, how to equip the people with civilization qualities and to develop good health habits, how to get to the good faith in management.It was especially needed to fully consider how to protect the interests of the local residents. The local residents with their productions and the living contents should be involed into the tourism plan instead of simple migrations. It reflects a kind of the planning idea of "people-oriented" which was also namely 
that "the quality of local residents of the life and the necessities of the tourists were equally important".

The tourists who entered into the ancient city of can be divided into two types.One of the two were short-term visitors and the other were tourists who could be considered as the local community members that stayed in the ancient city for a long time.The two different types of tourists had different awareness, ideas and behaviors of natural environment and social cultural.They also play different roles for the inhabitants of the ancient city.As tourists,protecting indigenous culture and maintaining good relationship between hosts and guests were equally responsible.

Through the observations and the understanding of the residents and the floating populations in lijiang,the old city takes these two basic ways.Lijiang has taken the "business - travel compound model" these years of tourism development merely.Most of the residents has moved out from the blocks.Instead,there has been the new type of commercial function activity.Now there are only 6000 people in the ancient city,a lot of indigenous people move out of the ancient city and a large number of migrants move into the city at the same time.Visitors can naturally involved in almost every building in physical space, but the feeling is only left over by history symbol or tourism "stage and props". This new form of life strike hardly on the $\mathrm{NaXi}$ culture of original residents, and the tourists complain that the commercial atmosphere was obvious,thus making the original residents get less economic benefits from tourism. Once the phenomenon has existed for a long time, it might damage the sustainable tourism development in lijiang.Therefore,there are necessities to avoid and reduce the phenomenons in the process of tourism development.At the second,there is also a part of "live - tourism complex mode" . the indigenous inhabitants of the ancient city make the full use of the space and so, tourists should have tourism activities by the premise of maximum respect to its illicit close space.This is just a small part of them and most of them has been developed into the inn. The author thinks that "the complex mode of live tourism" should be advocated in the tourism development in the old towns and the ancient villages.Organically uniting the production、 the life and the tourism of residents,desalting business sense and commercial atmosphere appropriately,vigorously strengthening the awareness of heritage culture and promoting natural culture atmosphere, creating conditions positively for the 
harmony between the "host" and the "guest" and developing the heritage tourism industry as the people's livelihood industries are also the ideas of the author.In order to maintain the authenticity of heritage culture more helpful, attention should be paid for the "time-honored brand", attention should be paid for inheritance of the traditional context and pulse having value,making full use of the profound historical culture, taking the culture as the basic connotation of development of commercial streets, forming strong cultural atmosphere in the mall,improving the culture grade of the mall in the mall of ancient city are also the ways to maintain the authenticity of heritage culture.According to the form of community participation in tourism development, the city should actively support the development of the cultural industry and service industry which were equipped with the tourism and try to let more local residents involve and manage the tourism of ancient city that could help the local residents get more profits. Then,these are conducive for the attitudes towards tourism by community residents and for the awareness, ideas, behavior for the ancient city better in tourism development.Effective measures should be taken properly limit tourists and scatter them to effectively ease environmental pressure in the city.In a word,it is necessary to make efforts to protect the reality of the heritage culture and properly handle the relationship between original residents and tourists to get the harmonious development in heritage tourism development.One of the important purposes to develop tourism is inherit culture to improve the people's livelihood in the tourism community.Therefore, the current heritage tourism development should renew the idea and transcend the developing mode of the attribute of industry economic.Meanwhile,the city should pay attention to play the function of tourism economy as well as give full play for the function of social culture and people's livelihood.In the meantime, the city might promote the construction of a harmonious society.Then,the tourism would become the people's livelihood industry or the social welfare industry.[11]

\section{Conclusion}

In the development of modern history, urbanization and modernization have been a trend of the world.Countless historic cities are sacrificed for the tourism development in the process of global.People value these ancient town which were 
narrowly escaped when they deeply regret for the destruction of the world heritage.Authenticity of culture is an important standard of the world heritage. The key to improve the quality of experience in ancient town tourism is to make the relationship between the hosts and the guests harmonious and the relationship should be paid full attention in tourism development. After years of rapid development of lijiang tourism, the city tourism industry should transform the single tourism industry of sightseeing to complex tourism industry when the city face the transition. In the process of tourism development, the city must opposite the eagerness for quick success and instant benefit and should be sure to have a long-term development perspective.Not only the building styles of material culture that were originally formed but also the people's original life forms which was a part of the non-material culture in the ancient city should be protected.And at the same time, the city should discuss the new development model and make the best efforts to protect the authenticity of heritage culture.Meanwhile,the city should adjust the relationship between the original residents and tourists actively. The city must respect and maintain the authenticity of the local culture and properly handle the relationship between the original residents and tourists to develop harmonious in the tourism development of cultural heritage sites.

\section{References}

[1] TaoWei.research about sustainable tourism development of China's "world heritage" [M]. Beijing: China Travel \& Tourism Press, 2001.

[2] Xie Ninggao. The world heritage is not equal to the tourism resources [J]. Beijing Planning Review. 2001. (6)

[3]Wei xiaoan. The relationship between the China' s world heritage protection or development of the and the development of tourism industry.[J/OL]. China Internet Information Center.2002-11-19.

[4]Fan lingyun. Zheng hao.The protection and the tourism development of the world culture and the natural heritage[J]. Planners BBS, 2003.26 (6)

[5]YanMei. Theory about culture construction of the sustainable development of China's "world cultural heritage" tourism [D]. Wuhan university, 2003.

[6]Liu changxue. The study about factors of push and pull of world heritage tourism

[J]. Tourism Tribune. 2005.(5) 
[7] MacCannell, D.S taged Authenticity: arrangments of social space in tourist Settings [J]. Journal of American Joural of Sociology, 1973, (79) : 589-602.

[8]Zhang xiaoping. The theory of "staged authenticity" in the anthropology of western tourism[J]. Thinking, 2003. 37 (4)

[9]Chen qinjian. Cultural tourism should reject "Pseudo folk" [J]. China Scholars Abroad.499.

[10]Zhang xiaoping. The theory of "staged authenticity" in the anthropology of western tourism[J]. Thinking, 2003. 45 (4)

[11]Cao shitu, Liu Xuezhen.Attemptment to talk about tourism and the livelihood of the people [J].Market of China, 2012 (1) : 128-129. 